\section{Geological Changes of Level}

IN a most friendly notice in your last issue of the Memoirs forming the first volume of the official Report of the Challenger Expedition, Prof. Huxley takes exception to a sentence in my short Introduction. "There seems to be sufficient evidence that all change; of level since the close of the Palæozoic period are in direct relation to the present coast lines," and he asks in what possible sense this can be the case.

I fully admit the criticism, and that the sentence as it stands does not explain itself.

That it is not a relation of ordinary parallelism Lyell's and D'Orbigny's maps of old coast lines, a map published by myself in "The Depths of the Sea," and particularly the beautiful later maps of Jurassic, Cretaceous, and Tertiary France by M. Delesse, abundantly show. I have explained my idea of the relation in position between the recent deposits and those of the Tertiary and Secondary periods in "The Depths of the Sea" (pp. 472-476) at some length. I believe that the Jurassic, the Cretaceous, and the Tertiary formations are essentially marginal deposits, and that their belts of deposition form approximately a series of contour bands upon an elevation which has persisted throughout a long series of local and general oscillations, the sum of which has raised the whole through a small vertical range. Such oscillations have also, doubtless, affected the bottom of the sea, but nowhere to such an extent as to modify in any important degree the conditions of the abyssal region.

Prof. Huxley says, "There is nothing, so far as I am aware, in the biological or geological evidence at present accessible, to render untenable the hypothesis that an area of the mid-Atlantic or of the Pacific sea-bed as big as Europe should have been upheaved as high as Mont Blanc and have subsided again any time since the Palrozoic epoch, if there were any grounds for entertaining it." I think however he will admit that the following Challenger data, if they can be established, afford at least a presumption against an oscillation of such a kind, at all events in post-Triassic times, beyond which it is difficult to stretch even the imagination.

The careful researches of my colleagues, Mr. Murray and the Abbé Renard, with which I have had the advantage of being familiar during their progress, have led as to the belief that (I) the chalk of the Cretaceous period was not laid down in what we now consider deep water, and that its fauna, consisting mainly of shallow-water forms, merely touches the upper limit of the abyssal fauna; and (2) that no beds exist in the series of known sedimentary rocks which correspond in composition and in structure with the beds now in process of formation in the abyssal sea ("The Atlantic," vol. ii. p. 299).

The hypothesis of the elevation of a mass of land equal to Europe and as high as Mont Blanc in the middle of one of the great ocean basins could in our present state of knowledge be defensible only on the supposition that it was a phenomenon of the same order as the elevation of some portion of our existing continental land, and there is now, to say the least, grave reason for doubting that any rock which is due to accumulations formed at depths over 2500 fathoms, the average depth of the basins to which Prof. Huxley refers, enters into the composition of any existing continent. The present land consists of a set of crystal. line rock-axes of various ages, with a long succession of sedimentary deposits, all of which give evidence of having been laid down in water of moderate depth, piled up upon and against them. Such a hypothesis therefore, besides being without a single fact in its support, would be met by a strong adverse argument from analogy, and would be, so far, in a worse case than the hypothesis of the origin of species by natural selection.

I thoroughly agree, however, with my friend Prof. Huxley that "the value of the great work which is now being brought before the public does not lie in the speculations which may be based upon it, but in the mass and the solidity of the permanent additions which it makes to our knowledge of natural facts," and I imagine that all of us who are engaged in that work look upon it as our first and paramount duty to present these natural facts which have been acquired as simply and as effectively as we can. Still the generalisations or impressions, or whatever they may be, of the few men selected to observe these facts are as much a part of the result of the Expedition as anything else, and I think it is also our duty to offer them to our fellow-workers for what they are worth.

Bonsyde, Linlithgow, November 6
"The First Volume of the Publications of the "Challenger" $-A$ Correction

THERE is a typographical error in my notice of the Challenger publications, published in last week's NATURE, for which I should, of course, be disposed to blame the printer, had it not been hinted to me that my handwriting is sometimes not so clear as might be wished.

I appear (p. 2) to agree with the proposition that " the deep-sea fauna presents us with many forms which are the dried and but little modified descendants of Tertiary and Mesozoic species."

As few things can be much wetter than the inhabitants of the ocean abysses, this opinion seems to be, to say the least, eccentric.

But "dried" should have been printed "direct," which was the word denoted by my graphic symbols.

4, Marlborough Place, Abbey Road, N.W., November 7

\section{Correspondence of Phenomena in Magnetic Storms}

THE Astronomer-Royal having lately received from the Observatory of Zi-ka-wei, in China (latitude $31^{\circ} \mathbf{1} 2^{\prime}$ north, longitude, from Greenwich, 8h. $6 \mathrm{~m}$. east), lithographed copies of the photographic traces of the declination and horizontal force magnets, extending from August I I to I4, and from August I 7 to 20 of the present year, has placed them in my hands for comparison with the Greenwich records. Some particulars of this comparison are herewith annexed. Greenwich time is used throughout.

A general examination of the two sets of curves shows that the disturbances were usually greater in magnitude at Greenwich than at $\mathrm{Zi} \cdot \mathrm{k} \cdot \mathrm{a} \cdot \mathrm{wei}$. Comparing the curves in detail, it is found that on August II, at $10.20^{1} \mathrm{a} . \mathrm{m}$, after a quiet period, the declination and horizontal force magnets at Greenwich both made a sudden start, which was the commencement of a magnetic disturbance, lasting until midnight. An apparently equally sudden start (from a quiescent state), in both declination and horizontal force, is shown on the $\mathrm{Zi}$-ka-wei curves, occurring in declination at $10.12 \mathrm{a} . \mathrm{m}$, and in horizontal force at $10.20 \mathrm{a} . \mathrm{m}$. (as nearly as the small scale on which the curves are drawn will allow measures to be made). This first motion was to decrease the west declination and increase the horizontal force at both places, A bold motion in the two Zi-ka-wei curves at II.3O a.m. (increase of declination, decrease of horizontal force) has corresponding decrease of horizontal force at Greenwich, not accompanied, however, by much motion in declination. And of numerous fluctuations occurring at Greenwich between noon and midnight of the same day, some appear to correspond with motions at $\mathrm{Zi}$-ka-wei, whil:t others do not.

A calm state follows at both places, until near noon of August 12. On this day at about YI.4O a.m. the magnets at Greenwich made a further start, and until 4 p.m. the movements were large. A corresponding start is also shown in both the $\mathrm{Zi}-\mathrm{ka}$-wei curves (commencing, according to the register, some minutes sooner than at Greenwich), the movements following being similarly large. Afterwards, until 6 a.m. of August I3, considerabie oscillation was nearly continually shown at Greenwich, there being especially a large change of declination between 7 and 9 p.m. (August I2); but there is no strongly-marked motion at the latter time at Zi-ka-wei, and the changes are throughout much smaller than at Greenwich. Later on Angust I 3 further oscillations occur at both places, but the separate motions are in no particular accordance. The period of disturbance seems definitely to come to an end at both places at $6 \mathrm{a} . \mathrm{m}$. on August 14

A period of quiet is broken at Greenwich on August 18, at I.45 p.m., by a sharp though small movement both in declination and horizontal force (increase of both). There is a correspording sharp increase (after quietude) of horizontal force at Zi ka-wei, but no change of declination. A bold increase of declination and decrease of horizontal force at Greenwich at 7 a.m. of August 19 is accompanied by a similar decrease of horizontal force at Zi-lia.wei, but with little change of declination. Bolder changes occur at the latter place at noon, but with comparatively small change at Greenwich. The magnets become quiet at both places at or near midnight of August 19.

The general result of this comparison of Greenwich and $\mathrm{Zi}$ $\mathrm{ka}$.wei curves appears to be that, after a quiet period, the first indication of disturbance, if sudden (it need not be large) occurs simultaneously or nearly so at both places, but that during the

${ }^{x}$ Approximately stated to be 10.30 in my previous letter (NATURE, vol. xxii. p. $3^{61}$ ), and so cuoted by Mr. Whipple (p. 558). The time above given is more exac:. 